\title{
THE VALUE OF CHEAP-TALK AND COSTLY SIGNALS IN COORDINATING MARKET ENTRY DECISIONS
}

\author{
James A. Sundali \\ University of Nevada, Reno \\ Darryl A. Seale \\ University of Nevada, Las Vegas
}

\begin{abstract}
Signaling occurs when a firm attempts to indicate, truthfully or not, its intended course of action. Competitors often use signaling in market entry situations to coordinate actions, or possibly to deter entry by other firms. This paper examines the value of cheap talk and costly signaling in a large group market entry game. Eighty subjects, twenty in each of four groups, participated in a computer-controlled decision making experiment. After learning the capacity of the market, subjects were given an opportunity to signal their intentions to enter or stay out. Following feedback of aggregate signals, subjects were asked to estimate the aggregate number of entry decisions they anticipated. Following the estimation task, subjects had to decide whether or not to enter the market, which varied in size from trial to trial. Results suggest that when no cost was imposed on signals (cheap talk), players significantly exaggerated their intentions to enter the market. When signals were costly, signaling behavior was more consistent with subsequent entry decisions. Overall, however, neither cheap talk nor costly signaling had much effect on actual market coordination, and aggregate results generally are consistent with Nash equilibrium predictions. The study concludes with a discussion of insights for researchers and management practitioners. Title: The Value of Cheap-talk and Costly Signals in Coordinating Market Entry Decisions
\end{abstract}

Decisions to enter or not to enter markets are among the most important strategic choices firms face. These decisions often involve significant investments of capital and human resources, and questions of market positioning, which some researchers view as the "essence of strategy" (Porter, 1996). Though the economic solution to the problem of market entry is often overly simplified, indicating that a risk-neutral, profit maximizing firm should base its entry decision on the net present value of expected profits (Oster, 1994), the strategy literature indicates there are countless ways a potential entrant might think about this type of decision and a myriad of variables or factors that may impact a firm's entry decision.

Given the diversity and inconsistency in market entry research, we have chosen to study a simple but fundamental problem that has not been addressed 
adequately in the literature: aggregate market entry coordination. Aggregate entry decisions that are coordinated poorly may result in situations of over-entry or under-entry. If over-entry occurs, the market may be served, but firms choosing entry face significant competitive pressures and lower profits. If under-entry takes place, the market may not be fully served, and firms choosing entry face negligible competition and higher profits. We also have chosen to study a factor that might affect aggregate market entry coordination: signaling.

Signaling occurs when a firm or decision maker attempts to indicate, truthfully or not, its intended course of action (Spence, 1974). Signals often manifest in market entry situations that involve strategic interdependence (Seale \& Sundali, 1999) - where the outcomes or payoffs to the firm depend not only on its decision, but also on the decisions of its competitors. In these situations, signaling may be a valuable tool to either coordinate actions, or possibly to deter entry by other competitors. To be effective, signals, which may take the form of verbal or written communication, or overt action, must be easily observable and made well in advance of the decisions and actions of rival firms.

Firms routinely make market entry decisions, decide between types of signaling activities, and attempt to interpret the signals they receive from their competitors. Considering this iterative process, several research questions are paramount. First, do decision makers use signaling, and, if so, do they use it strategically or truthfully? Second, how do decision makers interpret and use the signals made by competitors? Third, how does signaling affect market coordination?

Addressing these questions with traditional research methods using industry or firm level archival data presents several problems. First, many decisions, especially those not to pursue an opportunity, often are unobservable (Rapoport $\&$ Koput, 1993). Second, what should researchers conclude if a company decides not to enter? It may be that the firm determined entry would be unprofitable due to capacity constraints. But other confounding explanations are possible (e.g., a change in corporate leadership and strategy, lack of available capital, or the availability of other more profitable ventures). Third, there is little control over exogenous variables. For example, how can we know if competitors are communicating with each other? Due to possible legal concerns, communication, if any, is likely to occur discreetly and/or through unobservable channels. Given these problems, it is not likely that traditional post-hoc analysis of cross sectional data can provide a complete and meaningful understanding of the relevant research questions.

Recognizing these difficulties, we adopted a research design based on gametheoretic modeling. Such an approach has been gaining attention in strategic management, with some scholars welcoming its addition (Camerer, 1991; Saloner, 1994), and others cautioning its adoption, arguing that game theory comes with too much modeling freedom that can be used to justify and explain even irrational behavior (Postrel, 1994). Our interest here is not to join this discussion, or to add fuel to the fire. We hope simply to illustrate, with this particular problem, how game theory can inform strategic market entry decisions. 
The rest of this paper is organized as follows. The next section characterizes the structure, payoffs and equilibrium concepts for the $n$-person market entry game. The third section lists eight research hypotheses. Following the discussion of our research design and method, we characterize and compare the results of two experiments with large groups $(n=20)$ of subjects playing the market entry game with signaling. Finally, we conclude with a discussion of insights for researchers and management practitioners and suggestions for future research.

\section{The N-Person Market Entry Game}

Rapoport (1995) introduced the following $n$-person market entry game as a mechanism to test tacit coordination among large groups. Consider a group of $n$ symmetric players seated in a room where communication among them is controlled. On each trial (period), a different positive integer $c$ is announced publicly. The parameter $\mathrm{c}$, which varies from 1 to $n$, is interpreted as the "known capacity of the market." Once $c$ is announced, each player i must decide privately whether to enter $\left(\delta_{i}=1\right)$ or stay out $\left(\delta_{i}=0\right)$ of the market. Individual payoffs are determined each period by the following formula:

$$
H_{i}(\delta)= \begin{cases}v, & \text { if } \delta_{i}=0 \\ k+r(c-e), & \text { if } \delta_{i}=1\end{cases}
$$

where $H_{i}(\delta)$ is player i's payoff, given the vector of individual decisions for the period, and e $(0 \leq \mathrm{e} \leq \mathbf{n})$ is the number of market entrants. The parameters $\mathrm{v}$, $\mathrm{k}$, and $\mathrm{r}$ are real valued constants that remain fixed throughout the game. Like the value of $c$, they are common knowledge.

Rapoport (1995) showed that when $v=k$, the pure strategy Nash equilibrium prescribes $\mathrm{e}=\mathrm{c}$ or $\mathrm{e}=\mathrm{c}-1$ entrants. A Nash equilibrium is a profile of strategies (decisions), one for each player, such that if this profile were to occur, no single player would have an incentive to deviate from his or her decision. To illustrate, assume that $\mathrm{v}=\mathrm{k}=1$ and $\mathrm{r}=2$. If the market capacity (c) is 11 , the Nash equilibrium solution is for 10 or 11 players to enter. If 11 players enter, the payoff for entry is $1+2(11-11)=1$. The payoff for the 9 players who chose to stay out is also 1 . This outcome is in equilibrium because there is no incentive for any player to change his or her decision. If one of the 9 players that chose to stay out changes to enter, the payoff for entry will fall to $-1(1+2(11-12))$. If $\mathrm{e}=10$, the outcome is also a Nash equilibrium. Although the entry payoff is $3(1+2(11-10))$, an additional entrant would reduce this payoff to 1 , providing no incentive to enter. Thus for either 10 or 11 entrants, no player has an incentive to change his or her strategy.

Rapoport, Seale, Erev, and Sundali (1997; hereafter RSES) also have shown that the Nash equilibria prescribed in the market entry game are Pareto deficient. 
A comparison of equilibria and the Pareto optimal outcomes reveals that unless $c$ is very small, the number of entrants that maximizes total group payoff is approximately $\mathrm{e} / 2$. The difference in payoffs can be substantial. Consider the market entry game with parameters $\mathrm{n}=20, \mathrm{r}=2, \mathrm{k}=1$, and $\mathrm{v}=1$. If $\mathrm{c}=8$, a pure strategy Nash equilibrium is reached when $\mathrm{e}=7$, or $\mathrm{e}=8$, and total group payoff is $34((7 *(1+2(8-7))+13)$ or $20((8 *(1+2(8-8))+12)$, respectively. With the Pareto optimal number of entrants $(e=4)$, the total group payoff increases to $52((4 *(1+2(8-4))+16)$. As c increases, these results are even more striking. For example, when $\mathrm{c}=17$, the Pareto optimal number of entrants is 8 or 9 , and total group payoff increases to 164 . Clearly, group payoff increases substantially if players can successfully coordinate entry decisions in the direction of Pareto optimal outeomes.

In most real-world market entry situations, some form of communication among competitors is not only possible, but also likely. This communication often is valuable because it can help resolve coordination dilemmas, possibly avoiding situations of over-entry and lost profits. However, while serving a coordination function, such communication also may be strategic - an attempt to deter entry by potential competitors. In coordination games, like the market entry game, a signal constitutes a form of indirect communication where players, truthfully or not, attempt to indicate their type (Farrell, 1995). After the signal is sent and received, players then decide on a course of action where the outcomes are dependent on the types and actions of the players. Broadly defined, signals may be of two types - costly signals, or cheap-talk. Costly signals require the player to either (1) make a costly commitment to a course of action at the beginning of a game; or (2) communicate a signal without charge, but incur a charge if there is a change in this announced course of action. Cheap-talk is a form of communication or signaling that is cost-less, non-binding and payoff irrelevant (Farrell, 1995).

To incorporate these ideas into the $n$-person market entry game, we introduced limited communication in the form of signaling by amending the game as follows. After observing the market capacity for the trial, each subject was required to choose one of three signals: enter, not enter, or no indication. After all $n$ subjects made their signaling decisions, aggregate results showing only the number of players by type of signal were reported. Each subject then was asked to make his or her individual entry decision. With the introduction of signaling, the market entry game is transformed into a two-stage iterated game. Three signal choices combined with a binary entry decision results in the following six possible strategies:

1. Signal enter and then enter.

2. Signal enter and then do not enter.

3. Signal not enter and then enter.

4. Signal not enter and then do not enter.

5. Signal no indication and then enter.

6. Signal no indication and then do not enter. 
Each of the strategies allows for both costless (cheap talk) and costly signals. When signals are costless, the signaler is free to deviate from his or her announced plan of action, without penalty. Costless signals are payoff irrelevant. As such, they do not change the equilibrium solution to the market entry game. Regardless of which of the six strategies subjects choose, the outcome is in equilibrium if, and only if, $e=c$ or $e=c-1$. A signal that is costly can affect one's payoff, and hence may be considered credible. In the present market entry game, we allow subjects to issue one of the three signals, and then impose a cost if, and only if, the subject's action differs from the signal. To determine the equilibrium solution for the case of costly signals, we proceed as follows. Recall that from Equation 1, the payoff for entry is $k+r(c-e)$, and the payoff for not entering is $v$. Assume that the cost of issuing a signal and then choosing a different action is equal to $b$. Of the six pure strategies listed above, the cost b will be assessed only to strategies 2 and 3 . A cost or penalty is not assessed if subjects signal "no indication." It then can be shown that if $b>0$, strategy 1 dominates strategy 3 , and strategy 4 dominates strategy 2 . No matter what the outcome of a trial, a subject who takes an action that differs from his or her signal always will have an incentive to change to a strategy in which the signal and entry decision are consistent. With the four pure strategies that remain (1, $4,5,6)$, an outcome of the iterated market entry game with costly signals is in (sequential) equilibrium, if, and only if, $e=c$, or $e=c-1$.

\section{Research Hypotheses}

Although signaling often is not included in game-theoretic models, prior empirical research has shown that signaling can influence group decision behavior. Studies of costly signaling have been conducted by Ackerlof (1970), Spence (1974), Grossman (1981), Milgrom \& Roberts (1982), and Kreps (1994). As summarized by Ochs (1995), much of this experimental research has focused on coordination games with multiple, Pareto-ranked Nash equilibria. The general conclusion drawn from this research is that, under certain conditions, costly signals can help groups coordinate on Pareto dominant equilibria. Cheap talk, a form of non-credible communication, also has been shown to affect group decision behavior (Cooper, DeJong, Forsythe, \& Ross, 1989; Cooper, DeJong, Forsythe, \& Ross, 1992). The logic for this effect is offered by Farrell (1987): "Suppose that players' announced plans would, if actually played, constitute a Nash equilibrium. Then, we suggest, that equilibrium becomes focal. Moreover, if everyone expects such equilibria to be followed once announced, then cheap talk can help coordinate behavior to produce asymmetric equilibria" (pg. 35). Following this logic, it is reasonable to expect that both cheap talk and costly signaling may help coordinate outcomes in the market entry game.

Hypothesis 1: Signaling will improve group coordination of entry decisions. 
Because credibility may be at issue when signals are costless and non-binding, we expect costly signals will have a greater effect on improving coordination, thus:

Hypothesis 2: Costly signals will improve group coordination more than costless, non-binding signals.

As costly signals imply greater credibility and impart more meaningful, less ambiguous information to decision makers, we expect subjects receiving costly market entry signals to be better able to forecast subsequent market entry decisions. Accordingly,

Hypothesis 3: Costly signals will result in more accurate est $i$ mates of market entry.

Several experiments have examined variants of the $n$-person market entry game (Rapoport, 1995; Sundali, Rapoport \& Seale, 1995 (hereafter SRS); Rapoport, Seale \& Ordonez, 2002; Rapoport, Seale \& Winter, 2000; Camerer \& Lovallo, 1999; and RSES, 1997). Although there are substantial differences among these experiments, consistent findings emerge. First, there is a remarkably high level of coordination (correlation) between the market capacity and the number of entrants, as predicted by the pure strategy Nash equilibrium solution. This coordination is achieved early in the experimental sessions and does not diminish with repeated play. A second finding that is reported consistently in the market entry literature cited above is that subjects do not move away from equilibrium predictions over time in the direction of Pareto optimal outcomes. Despite the large payoff incentive associated with Pareto outcomes (see previous section), the difficulty of tacit coordination increases exponentially in the number of players. With $n=20$ players, we expect that the limited signaling abilities introduced in the present study will have no effect in moving the group toward Pareto levels of entry, thus:

\section{Hypothesis 4: Signaling will not move group outcomes away from equilibrium predictions in the direction of Pareto optimal levels of entry.}

Perhaps the most important notions of game-theoretic reasoning are that players act rationally and attempt to maximize their expected utility. This reasoning assumes, in essence, that players behave strategically. Although there are abundant empirical studies that cast doubt on this assumption, claiming that decision makers exhibit bounded or limited rationality, or are vulnerable to systematic biases in their reasoning, the preponderance of evidence in this vast literature supports the tenets of strategic play. Additionally, while these key assumptions of rationality often are under attack, no powerful alternative theories have been 
proposed (Roth, 1995). At issue is not that players behave strategically, rather it is the degree of strategic behavior. Thus, in the market entry game, we expect players to use signals strategically when signaling is costless and non-binding, and to signal truthfully when deviations from signals to actions are costly.

Hypothesis 5: Players will attempt to use signaling strategically when signals are costless and non-binding.

When signals are costless and non-binding, they have no effect on individual payoffs. Game theory proposes that if a variable has no affect on payoffs, then it is not credible and should be ignored. Thus, even though subjects will use such signals strategically, the signals should have no impact on the decisions of subjects. This leads to the next hypothesis:

Hypothesis 6: Signals that are costless and non-binding will be ignored and will have no affect on the decisions of subjects.

In addition to the six research hypotheses described above, the following two outcomes, which serve as manipulation checks for the experimental design, also are expected:

Hypothesis 7: The number of entry decisions will increase with the market capacity.

Hypothesis 8: With the introduction of costly signals, subjects will abandon dominated strategies (\#2 and \#3) where signal and subsequent behavior are inconsistent.

\section{Design And Method}

Eighty subjects participated in the experiment. The subjects were divided into four twenty-person groups. Two groups participated in a cheap talk (CT) condition, and two groups participated in a costly signaling (CS) condition. The subjects consisted of undergraduate and graduate students, and a few university employees who responded to an advertisement in the school newspaper.1 The advertisement promised payoffs contingent upon performance, from $\$ 5$ to $\$ 50$ for participation in a two-hour computer controlled experiment in economic decision making.

The experiment was conducted at the Enterprise Room at the University of Arizona. The laboratory contained over twenty networked microcomputers, separated by both built-in features and wide aisles. As subjects entered the laboratory, they were seated randomly at one of the workstations and asked to read a copy of the instructions placed next to the workstation. The instructions welcomed subjects to the lab and informed them that if they 
made careful decisions, they had an opportunity to earn a considerable sum of money, which would be paid to them in cash at the end of the experiment.2 After all subjects read the instructions, one of the experimenters guided them through an example, highlighting the requirements of the task, and sample payoff calculation. After subjects were given an opportunity to ask questions, the experiment began.

Each subject then was given an endowment of 20 francs $(1$ franc $=\$ 0.25)$ and advised that his/her earnings (losses) accumulated during the experiment would be added to (subtracted from) this endowment. The experiment lasted 50 trials, with each trial consisting of three steps. In the first step, the computer announced the capacity of the market for the present trial, and subjects had an opportunity to either (1) signal their intention to enter the market, (2) signal their intention to not enter the market, or (3) signal no indication regarding their intention. In Condition CT, signals were costless and non-binding; there was no penalty when entry decisions deviated from entry signals. In Condition CS, giving a signal also was costless; however, if subjects' subsequent entry decisions did not conform to their original signals, they were penalized $1 / 2$ franc. Note that subjects signaled "no indication" (option 3, above), they were free to enter or not enter without penalty. In the second step, after all subjects made their signaling decisions, the computer displayed the aggregate results of signaling (i.e., the total number of subjects signaling enter, not-enter, and no-indication). Signaling decisions were not reported at the individual level. Subjects then were prompted to estimate the total number of entrants for the current trial. To motivate accurate estimates, subjects were paid an additional $\$ 0.10$ for every trial where their estimate was within \pm 1 of the true number of entrants. In the third and final step of each trial, subjects were asked to make a binary decision - enter or not enter the market - based on the payoff formula given in Equation 1. Notice that subjects could guarantee themselves a positive payoff by not entering the market. The 50 trials were divided into 5 blocks of 10 trials each. In each block, the value of $\mathrm{c}$ was sampled without replacement from the set $\{1,3, \ldots, 19\}$. To reduce the burden of computation, on each trial, subjects were presented with a table that summarized payoffs for all possible number of entrants, given the current value of $c$.

After all subjects made their entry decisions, the computer displayed the number of entrants (e) for the trial, and their current and cumulative payoffs. After all subjects reviewed this feedback, the next trial began. Subjects were given paper and pencil to make notes or record information they deemed important. At the conclusion of the experiment, subjects were paid individually in cash, thanked, and dismissed from the lab. Each session lasted approximately two hours. Note that there was no between-group treatment. Conducting two groups per condition allowed us to assess the stability of group outcomes. 


\section{Results}

The results are organized into three sections. First, we examine signaling behavior between Conditions CT and CS. Then, we summarize estimates of entry decisions between conditions and across experimental blocks. Finally, we examine entry decisions between conditions, comparing our results to the SRS (1995) market entry study conducted without signaling. The design of the current experiment is identical to SRS, with three exceptions. In SRS, subjects did not have the ability to signal, data were collected for three groups $(n=20)$ of subjects, and the game was played for 100 trials rather than 50 . The fewer number of trials in conditions CT and CS was due to the increased demands of the signaling and estimating aspects of the task.

\section{Signaling Results}

To compare entry signals between Conditions CS and CT, and to test for block effects, a condition by $\mathrm{c}$ by block $(2 \times 10 \times 5)$ ANOVA, with block as a repeated measure, was conducted. 3 The results, shown in Table 1, show significant between subjects main effects for Condition $(F=216.9, p=0.000)$ and $\mathrm{c}(\mathrm{F}=22.9, \mathrm{p}=0.000)$ and a significant within subject interaction effect on block* ${ }^{*}(F=1.62, p=0.038)$. The interpretation of these results is straightforward, and is illustrated in Figure 1. This figure displays the mean number of entry, no-entry, and no-indication signals combined across group and block, by market capacity for the two conditions. Condition CT appears as the solid line and Condition CS as the dashed-line. The top panel of Figure 1, consistent with the ANOVA results, shows that the number of entry signals increased with market capacity, and the level of entry signaling was much greater in Condition CT than in Condition CS. There is no evidence that the number of entry signals changed over time (block) in either condition. The fact that the number of entry signals did not decline across blocks in condition CS indicates that many subjects chose to continue signaling even though they had the option of signaling no indication. Note also that entry signals are over-specified for small values of $\mathrm{c}$, and under-specified for large values of $\mathrm{c}$. The mean number of signals indicating $\mathrm{n}^{-}$-ntry, shown in the middle panel of Figure 1, declined with market capacity, and did not differ between conditions. No-indication signals, shown in the bottom panel of Figure 1, occurred more frequently in Condition CS, but did not vary by market capacity. Clearly, the difference between conditions is the shift from entry to no indication signals between conditions CT and CS; with the introduction of costly signals, subjects generally ceased their exaggeration of entry signals.

\section{Estimates of Entry}

Recall that subjects were motivated to estimate the number of market entrants accurately; they were paid $\$ 0.10$ every time their estimate was within \pm 1 of the actual number of market entrants. To test for block effects with the number of 
accurate entry estimates as the dependent measure, a condition by $\mathrm{c}$ by block $(2 \times 10 \times 5)$ ANOVA, with block as a repeated measure, was conducted. This analysis, shown in Table 2, revealed significant between subjects main effects for condition $(F=21.2, p=0.000), c(F=3.0, p=0.020)$, and the condition* ${ }^{*}$ interaction $(\mathrm{F}=3.2, \mathrm{p}=0.014)$. There were also within subject effects on block $(\mathrm{F}=11.2, \mathrm{p}=0.000)$, block* condition $(\mathrm{F}=4.5, \mathrm{p}=0.003)$, block* ${ }^{*}(\mathrm{~F}=1.9, \mathrm{p}$ $=0.008)$ and block ${ }^{*}$ condition $*(F=1.6, p=0.036) .4$ Again, the interpretation is straightforward and can been seen in Figure 2. The top panel of this figure displays the mean number of subjects that estimated total market entrants accurately on each trial by value of $c$ and condition. The data are averaged over block. It is clear that for all values of c, except 1 and 19, subjects in CS provided more accurate estimates of total entrants than subjects in CT, and that accuracy improved over time. Additionally, the effect for $\mathrm{c}$ suggests that subjects in the CT condition made more accurate estimates for low and high values of $c$, while in the CS condition accuracy was better for middle values of $\mathrm{c}$. The bottom panel of Figure 2 captures the block by condition interaction. This interaction implies that not only did subjects in Condition CS make more accurate estimates, but also that accuracy improved over time (block) at a greater rate. The main effects for $c$ indicate that subjects' ability to forecast entry decisions accurately was dependent on the market capacity.

Table 1

Repeated Measures Anova - Signals

Tests of Hypotheses for Between Subject Effects

\begin{tabular}{lcrrrl}
\hline Source & df & Sum of Squares Mean Square & F Value & p Value \\
\hline Intercept & 1 & 22050.0 & 22050.0 & 2306.5 & 0.000 \\
Condition & 1 & 2073.7 & 2073.7 & 216.9 & 0.000 \\
C & 9 & 1972.7 & 219.2 & 22.9 & 0.000 \\
Condition*C & 9 & 160.0 & 17.8 & 1.9 & 0.119 \\
Error & 20 & 191.2 & 9.6 & & \\
\hline
\end{tabular}

Tests of Hypotheses for Within Subject Effects

\begin{tabular}{lccccc}
\hline Source & df & Sum of Squares Mean Square & F Value & p Value \\
\hline Block & 4 & 12.6 & 3.1 & 0.92 & 0.458 \\
Block*Condition & 4 & 24.4 & 6.1 & 1.78 & 0.141 \\
Block ${ }^{*}$ C & 36 & 199.8 & 5.6 & 1.62 & 0.038 \\
Block* Cond ${ }^{*}$ C & 36 & 75.9 & 2.1 & 0.62 & 0.946 \\
Error(Block) & 80 & 273.8 & 3.4 & & \\
\hline
\end{tabular}


Figure 1

Mean Number of Signals by Condition and market Capacity
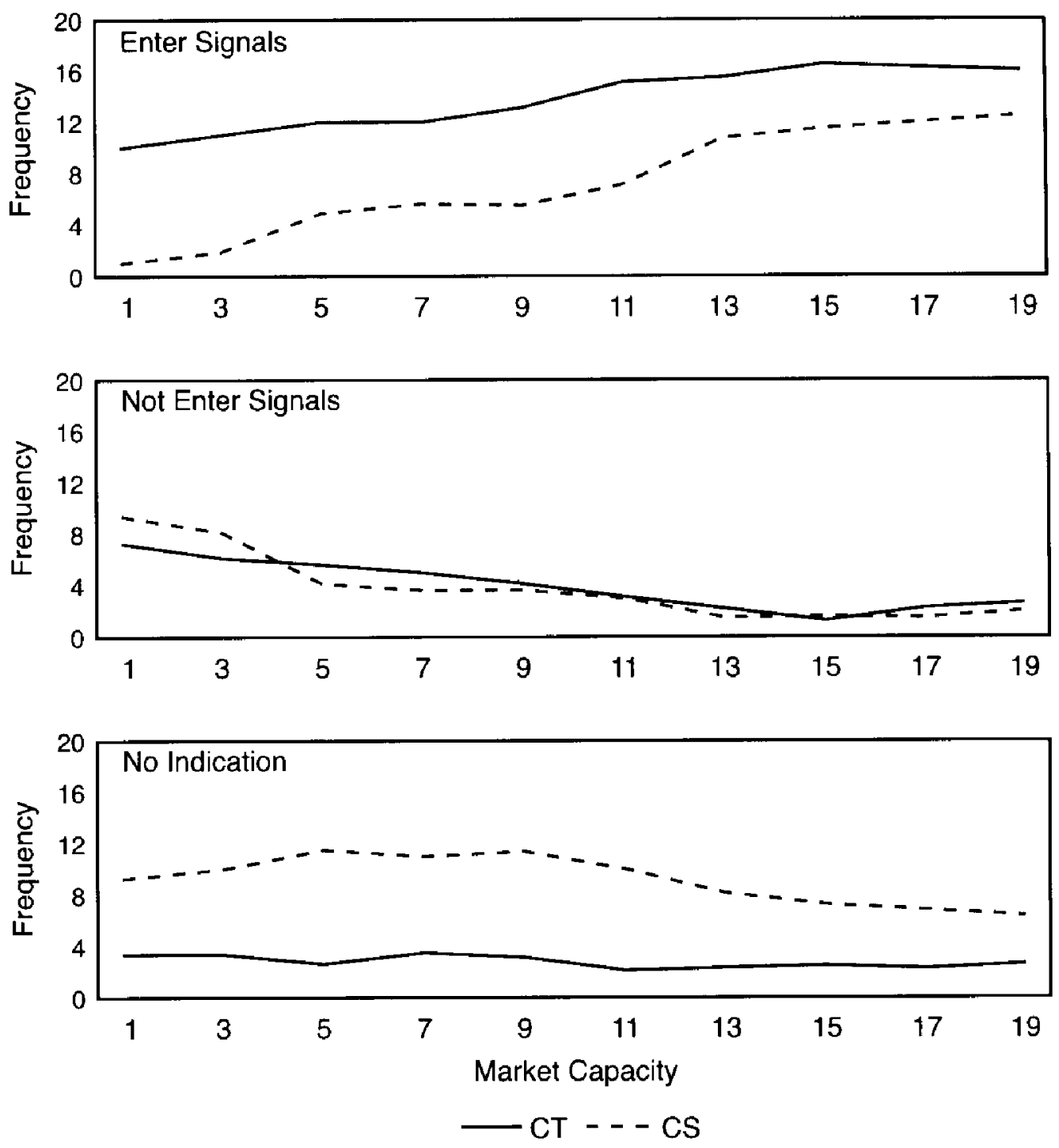

Figure 3 diagrams the mean and standard deviation of entry estimates by market capacity and condition. It is apparent that the variance of the estimates of subjects in the CT condition is significantly higher than in the CS condition. Some subjects in the CT condition gave estimates that were far from the market capacity. For example, for $\mathrm{c}$ values of $1,3,5$, and 7 , the high estimate for the number of entrants in the CT (CS) condition was $15,15,19$ and $19(7,14,10$, $13)$, respectively. Thus, not only are there fewer accurate estimates in the CT condition, but the magnitude of error in the CT condition also is significantly higher. 
Table 2

Repeated Measures Anova - Estimates

Tests of Hypotheses for Between Subject Effects

\begin{tabular}{lcrrrr}
\hline Source & df & Sum of Squares Mean Square & F Value & p Value \\
\hline Intercept & 1 & 21197.4 & 21197.4 & 1005.3 & 0.000 \\
Condition & 1 & 447.0 & 2073.7 & 21.2 & 0.000 \\
C & 9 & 569.0 & 219.2 & 3.0 & 0.020 \\
Condition*C & 9 & 611.0 & 67.9 & 3.2 & 0.014 \\
Error & 20 & 421.7 & 21.1 & & \\
\hline
\end{tabular}

Tests of Hypotheses for Within Subject Effects

\begin{tabular}{lccccc}
\hline Source & df & Sum of Squares Mean Square & F Value & p Value \\
\hline Block & 4 & 475.8 & 118.9 & 11.2 & 0.000 \\
Block ${ }^{*}$ Condition & 4 & 189.1 & 47.3 & 4.5 & 0.003 \\
Block ${ }^{*}$ C & 36 & 735.0 & 20.4 & 1.9 & 0.008 \\
Block*Cond*C & 36 & 624.1 & 17.3 & 1.6 & 0.036 \\
Error(Block) & 80 & 848.8 & 10.6 & & \\
\hline
\end{tabular}

To examine the relationship, if any, between estimates of entry and subsequent entry decisions, we grouped subjects' estimates into one of three categories: the estimate was (1) greater than the market capacity, (2) equal to the equilibrium prediction of $\mathrm{c}$ or $\mathrm{c}-1$, or (3) less than the equilibrium prediction. Then, we computed the proportion of estimates by whether or not the subject entered the market. These proportions are reported in the top panel of Table 3. Averaged across conditions, the percentage of subjects that chose to enter when their estimate was greater (less) than the market capacity (c) was $28 \%(75 \%)$. This indicates that subjects' entry decisions were highly correlated with their estimates of whether or not entry would be profitable. When the estimate of number of entrants was equal to $\mathrm{c}$ or $\mathrm{c}-1$, the average Nash equilibrium prediction, $62 \%$ of subjects chose entry; interpretation of this result is not straightforward since it is unknown if a subject included her or himself in the aggregate entry estimate. An ANOVA on entry decisions with estimate category and condition $(3 \times 2)$ as independent variables produced a main effect for estimate category ( $F$ $=299.7, p=0.000)$, no main effect for condition $(F=0.0, p=0.892)$, and an estimate category by condition interaction effect $(F=6.08, p=0.002)$. In sum, the accuracy of estimates was better in the CS condition, and subject estimates of the number of likely entrants was highly correlated with entry decisions in a predictable and rational manner. 
Figure 2

Mean Number of Accurate Estimates of Entry Decisions by Condition
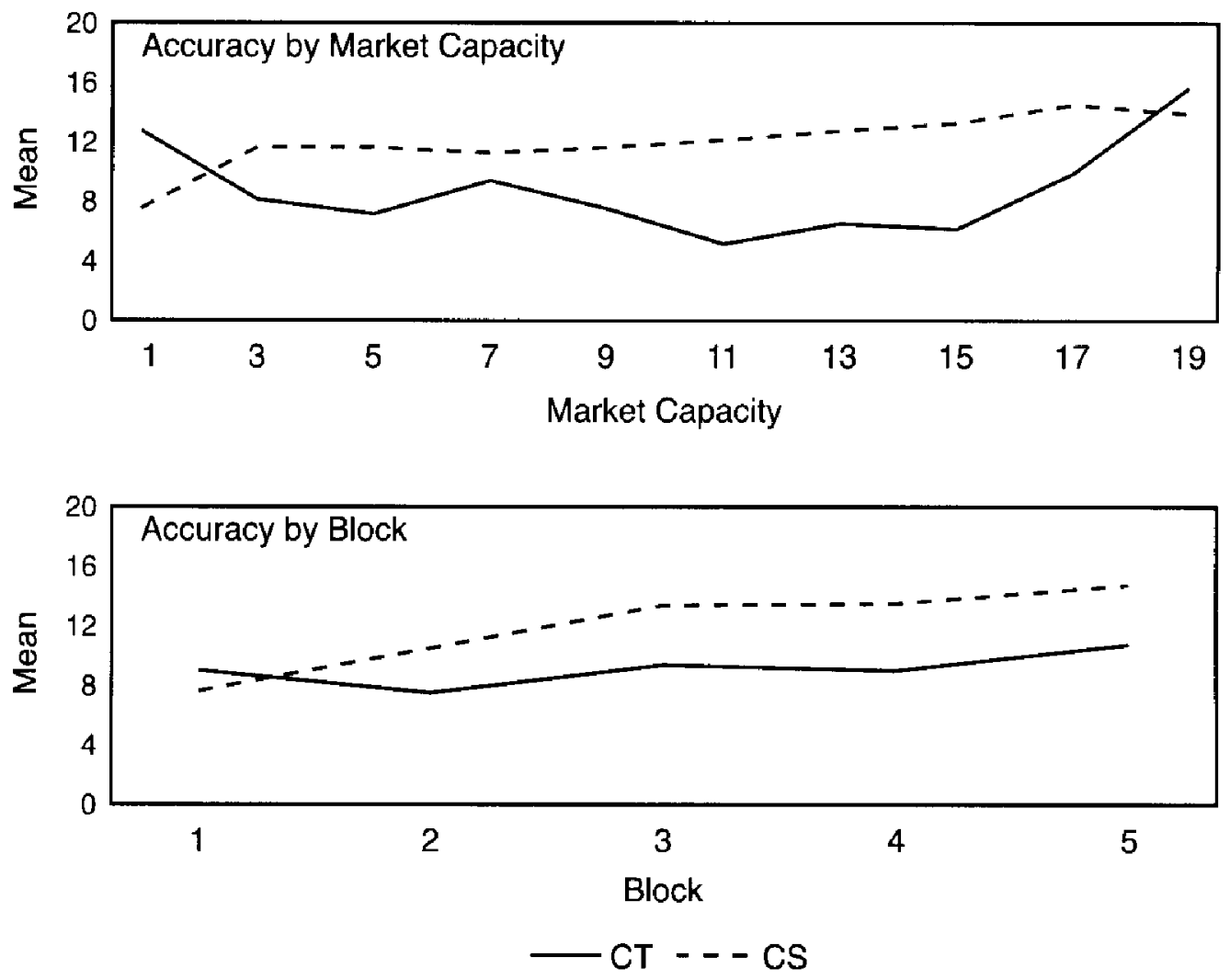

\section{Entry Decisions}

To analyze entry decisions and compare these results to SRS, we conducted a condition ${ }^{5}$ by $\mathrm{c}$ by block ( $3 \mathrm{X} 10 \mathrm{X} 5$ ) ANOVA, with block as a repeated measure. This analysis, reported in Table 4 , revealed a significant main effect for $c(F=464.6, p=0.000)$, no main effect for condition or block, and significant interaction effect on block ${ }^{*} \mathrm{c}(\mathrm{F}=1.67, \mathrm{p}=0.020)$. This analysis argues that the frequency of entry decisions depends greatly on $\mathrm{c}$ and does not differ by signaling condition. The number of entry decisions by condition and market capacity is reported in Figure 4. These data (reported only for the first 5 blocks of SRS) show that the number of entrants is highly correlated with $c$. More detailed analysis (not shown here) reveals that, with a single exception, the correlation between $\mathrm{c}$ and e exceeds 0.90 for all three conditions across the five blocks. 
Table 2

\section{Repeated Measures Anova - Estimates}

Tests of Hypotheses for Between Subject Effects

\begin{tabular}{|c|c|c|c|c|c|}
\hline Source & df & Sum of Squares & Mean Square & F Value & p Value \\
\hline Intercept & 1 & 21197.4 & 21197.4 & 1005.3 & 0.000 \\
\hline Condition & 1 & 447.0 & 2073.7 & 21.2 & 0.000 \\
\hline C & 9 & 569.0 & 219.2 & 3.0 & 0.020 \\
\hline Condition ${ }^{*} \mathrm{C}$ & 9 & 611.0 & 67.9 & 3.2 & 0.014 \\
\hline Error & 20 & 421.7 & 21.1 & & \\
\hline
\end{tabular}

Tests of Hypotheses for Within Subject Effects

\begin{tabular}{lccccc}
\hline Source & df & Sum of Squares Mean Square & F Value & p Value \\
\hline Block & 4 & 475.8 & 118.9 & 11.2 & 0.000 \\
Block* Condition & 4 & 189.1 & 47.3 & 4.5 & 0.003 \\
Block ${ }^{*}$ C & 36 & 735.0 & 20.4 & 1.9 & 0.008 \\
Block*Cond*C & 36 & 624.1 & 17.3 & 1.6 & 0.036 \\
Error(Block) & 80 & 848.8 & 10.6 & & \\
\hline
\end{tabular}

To examine if signaling was effective in moving the groups away from equilibrium predictions in the direction of Pareto optimal outcomes, we computed two additional measures: mean distance from equilibrium, and mean subject payoff. Mean distance from equilibrium was computed from Equation $\# 2$ below:

$$
\sum|\min (\mathrm{e}-\mathrm{c} ; \mathrm{e}-\mathrm{c}-1)|
$$

where the minimum of $\mathrm{e}-\mathrm{c}$ or $\mathrm{e}-\mathrm{c}-1$ accounts for the two entry values that are in equilibrium for a single value of $c$. The results of this analysis are displayed in Figure 5. Although the results for SRS are shown over 10 blocks of trials, they are directly comparable to the signaling conditions through the first 5 blocks. For SRS, the mean distance from equilibrium fell from 2.1 in block 1 to 0.8 in block 2 , then averaged to less than 1.0 throughout the remaining blocks. In Condition CT, the mean distance measure initially rose for the first few blocks, then declined to less than 1.0 by block 5 . Although the mean distance measure was consistently smaller in Condition $\mathrm{CS}$, a condition by $\mathrm{c}$ by block $(3 \mathrm{X} 10 \times 5)$ ANOVA, with block as a repeated measure, indicated that these differences were not significant. Thus, there is no evidence that the signaling groups performed better or worse than the SRS groups, or any indication that the mean deviation decreased with experience. 
Table 3

The Effects of Estimates on Entry Decisions

\begin{tabular}{lcc}
\hline Condition $C \boldsymbol{T}$ & \multicolumn{2}{c}{ Entry Percentage } \\
\cline { 2 - 3 } & Not Enter & Enter \\
Estimate Category & $73.9 \%$ & $26.4 \%$ \\
Estimate $>\mathrm{c}$ & $34.9 \%$ & $65.1 \%$ \\
Estimate $=\mathrm{c}$ or $\mathrm{c}-1$ & $21.0 \%$ & $79.0 \%$ \\
Estimate $<\mathrm{c}-1$ & & \\
\hline
\end{tabular}

\begin{tabular}{lcc}
\hline Condition $\mathrm{CS}$ & \multicolumn{2}{c}{ Entry Percentage } \\
\cline { 2 - 3 } & Not Enter & Enter \\
Estimate Category & $70.5 \%$ & $29.4 \%$ \\
Estimate $>\mathrm{c}$ & $42.0 \%$ & $58.0 \%$ \\
Estimate $=\mathrm{c}$ or $\mathrm{c}-1$ & $29.5 \%$ & $70.5 \%$ \\
Estimate $<\mathrm{c}-1$ & & \multicolumn{2}{c}{-1}
\end{tabular}

Anova - Estimate Affects on Entry Decisions

\begin{tabular}{lcrrrr} 
Source & df & Sum of Squares Mean Square & F Value & p Value \\
\hline Model & 5 & 137.8 & 26.6 & 122.3 & 0.000 \\
Condition & 1 & 0.0 & 0.0 & 0.0 & 0.892 \\
Estimate Category & 2 & 130.1 & 65.1 & 299.1 & 0.000 \\
Estimate Category* C & 2 & 2.6 & 1.3 & 6.1 & 0.002 \\
\hline
\end{tabular}

Our final analysis of entry decisions tracks the mean subject payoff per trial. Since the payoff formulas between the two studies were identical, with the exception of the possible signaling penalty in CS, the results are directly comparable through the first 5 blocks. A condition by $\mathrm{c}$ by block ( $3 \mathrm{X} 10 \times 5)$ ANOVA, with block as a repeated measure, indicated no significant effects. Figure 6 clearly shows that, with the single exception of block 4 in Condition $\mathrm{CT}$, the mean subject payoff per block approaches 1.0 , the equilibrium payoff. Again, there is no evidence that the signaling groups performed better or worse than the SRS groups, or any signs that the mean subject payoff changed over time. Further, combining the results presented in Figures 5 and 6 shows that there was no movement toward Pareto optimal outcomes; such a movement would result in an increase in the mean distance measure (Figure 5) and mean subject payoff (Figure 6). 
Table 4

Repeated Measures Anova - Entry Decisions

Tests of Hypotheses for Between Subject Effects

\begin{tabular}{lcrrrr}
\hline Source & df & \multicolumn{1}{c}{ Sum of Squares Mean Square } & F Value & p Value \\
\hline Intercept & 1 & 33525.4 & 33525.4 & 14977.8 & 0.000 \\
Condition & 2 & 3.2 & 1.6 & 0.7 & 0.498 \\
C & 9 & 9358.2 & 1039.8 & 464.6 & 0.000 \\
Condition ${ }^{*} \mathrm{C}$ & 18 & 34.8 & 1.9 & 0.9 & 0.621 \\
Error & 40 & 89.5 & 2.2 & & \\
\hline
\end{tabular}

Tests of Hypotheses for Within Subject Effects

\begin{tabular}{lccccc}
\hline Source & df & Sum of Squares Mean Square & F Value & p Value \\
\hline Block & 4 & 7.0 & 1.7 & 0.57 & 0.687 \\
Block $^{*}$ Condition & 8 & 11.1 & 1.4 & 0.46 & 0.886 \\
Block $^{*}$ C & 36 & 183.6 & 51.0 & 1.67 & 0.018 \\
Block*Cond*C & 72 & 306.7 & 4.3 & 1.39 & 0.045 \\
Error(Block) & 160 & 489.8 & 3.1 & & \\
\hline
\end{tabular}

Figure 4

Mean Number of Entry Decisions by Condition and Market Capacity

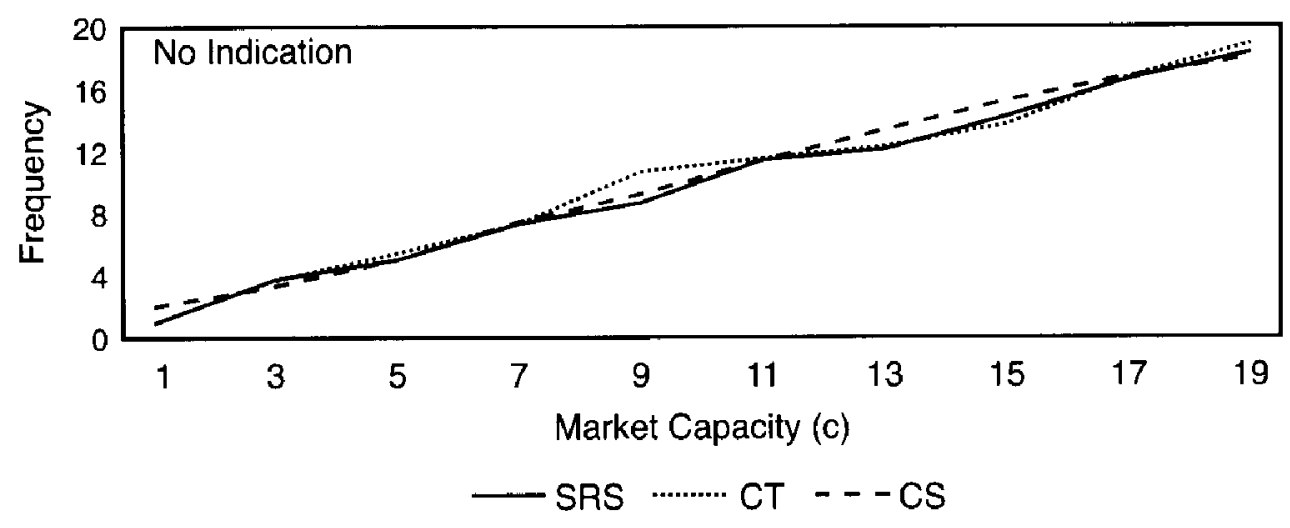

The results suggest that signaling did not affect aggregate market coordination. Given this, an obvious question arises - why did subjects continue to signal when they had the option of not indicating a signal? One explanation is that subjects may be signaling strategically - attempting to discourage entry by others in the experiment. An alternative explanation is that subjects may be attempting to signal to improve overall group coordination. To explore these alternative explanations further, we examine in Table 5 the relationship between signaling and subsequent entry decisions. 


\section{Figure 5}

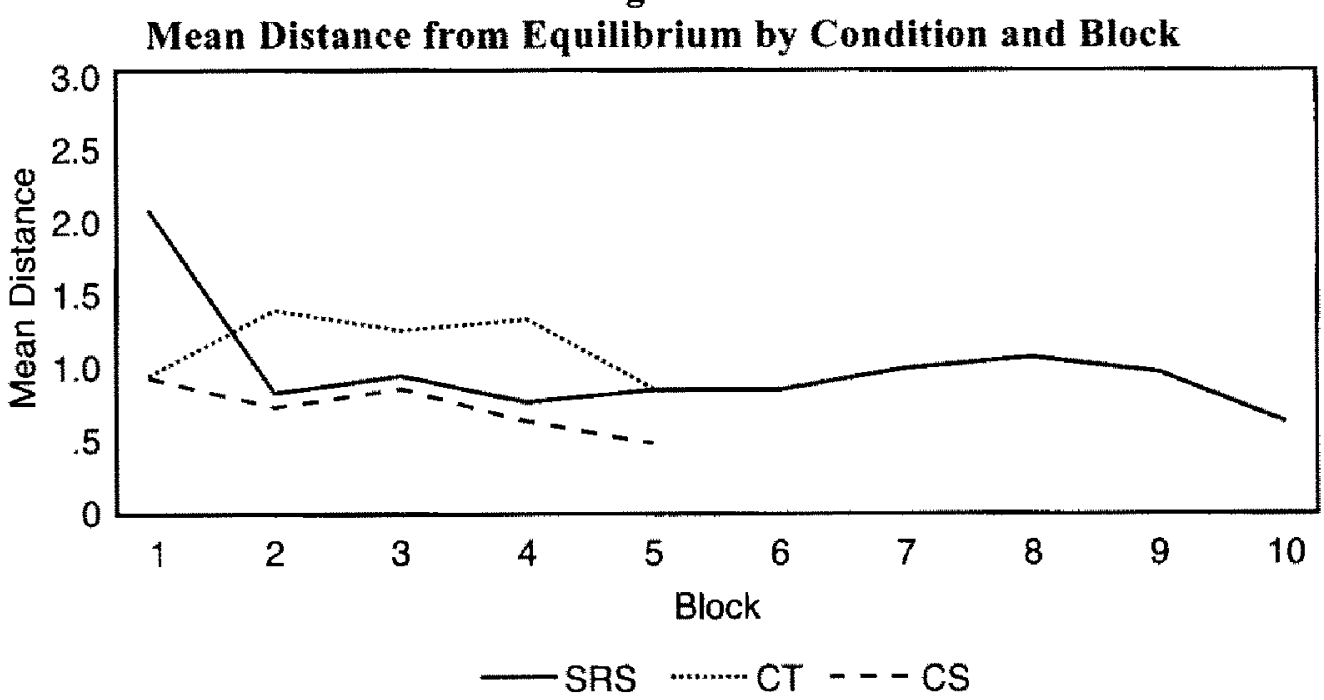

Figure 6

Mean Payoff per Trial by Condition and Block

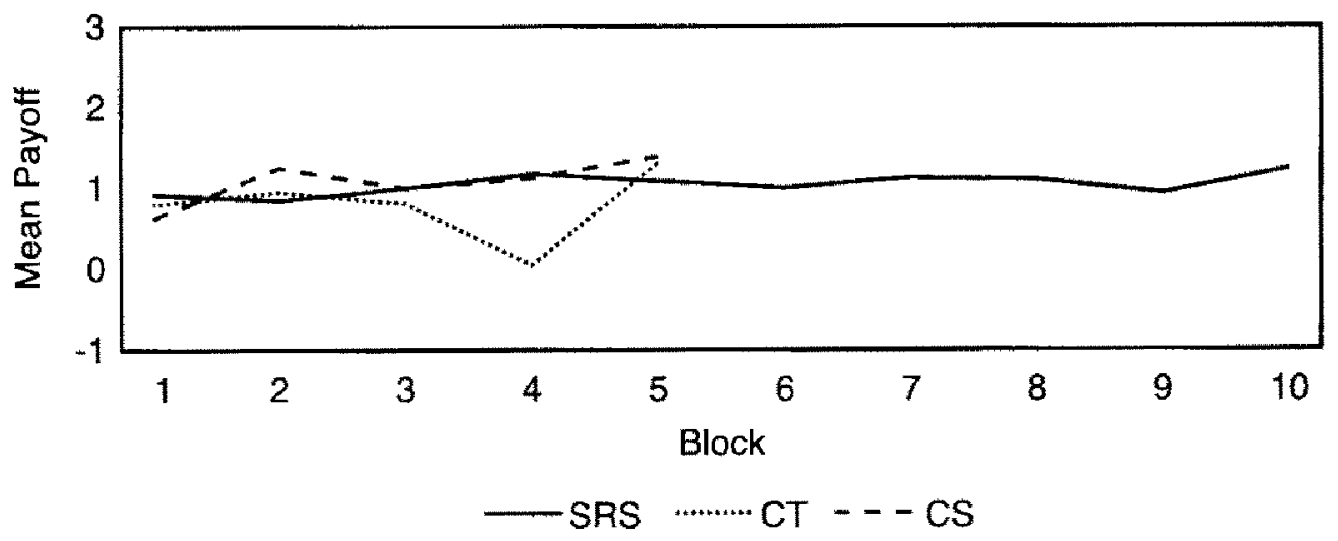

Table 5 reports the number of entry and no-entry decisions by type of signal. Conditions CT and CS are shown on the top and bottom halves of the table, respectively. In each condition we examine 2000 signals ( 2 groups $x 20$ subjects $x 50$ trials). The table organizes entry signal by subsequent entry decision. In Condition CT, subjects signaled no enter $389(19 \%)$ times, signaled enter 1372 $(69 \%)$ times, and signaled no indication $239(12 \%)$ times. In Condition CS, there is a similar frequency $(376,19 \%)$ of no entry signals. However, consistent with the results reported in Figure 1, there is a pronounced shift from entry signals $(728$, or $36 \%$ ) to no indication signals $(896$, or $45 \%$ ). Even more interesting is the measure of consistency between signal and decision by condition. In Condition CS, signals and decisions were consistent $97 \%((358+712) /(376$ $+728)$ ) of the time; entry signals were consistent with entry decisions $98 \%$ of 
the time, while no entry signals were consistent with no entry decisions $95 \%$ of the time. When signaling was costless and non-binding, consistency dropped to $64 \%$, with entry signals consistent with entry decisions $60 \%$ of the time, and no entry signals consistent with no entry decisions $78 \%$ of the time. This finding, combined with the shift from entry to no indication signals described earlier, clearly shows that a large number of subjects in Condition CT engaged in strategic signaling. Analysis of data at the subject level (not reported here) confirms this result. Thus, some subjects attempted to signal strategically when there was no cost or penalty for inconsistent action. When a cost was imposed, subjects retreated to no indication signals.

Table 5

Entry Decisions by Types of Signal

\begin{tabular}{|c|c|c|c|c|}
\hline \multicolumn{5}{|l|}{ Condition $C T$} \\
\hline \multirow[b]{2}{*}{ Enter Decision } & \multicolumn{4}{|c|}{ Signal } \\
\hline & Not Enter & Enter & No Indication & Total \\
\hline No Enter & 302 & 550 & 147 & 999 \\
\hline Enter & 87 & 822 & 92 & 1001 \\
\hline Total & 389 & 1372 & 92 & 2000 \\
\hline \multicolumn{5}{|l|}{ Condition CS } \\
\hline & \multicolumn{4}{|c|}{ Signal } \\
\hline Enter Decision & Not Enter & Enter & No Indication & Total \\
\hline No Enter & 358 & 16 & 621 & 995 \\
\hline Enter & 18 & 712 & 275 & 1005 \\
\hline Total & 376 & 728 & 896 & 2000 \\
\hline
\end{tabular}

\section{Discussion of Hypotheses}

We briefly discuss the empirical support for each hypothesis and summarize the findings in Table 6 . 
Table 6

Support for Hypotheses

\section{Hypothesis}

Outcome

1. Signaling will improve group coordination of entry decisions.

Not Supported

2. Costly signals will improve group coordination more than costless, non-binding signals.

Not Supported

3. Costly signals will result in more accurate estimates of market entry. Supported

4. Signaling will not move group outcomes away from equilibrium predictions in the direction of Pareto optimal levels of entry.

5. Players will attempt to use signaling strategically when signals are costless and non-binding.

6. Signals that are costless and non-binding will be ignored and will have no affect on the decisions of subjects.

Supported

Supported

Not Supported

7. The number of entry decisions will increase with the market capacity.

Supported

8. With the introduction of costly signals, subjects will abandon dominated strategies ( $\# 2$ and $\# 3$ ) where signal and subsequent behavior are inconsistent.

Supported

- Hypothesis 1: Signaling will improve group coordination of entry decisions. (Not supported) There was no evidence to suggest that group coordination improved from prior experiments. There was no significant difference in the number of entrants or the correlation between $\mathrm{c}$ and e across CT, CS or SRS.

- Hypothesis 2: Costly signals will improve group coordination more than costless, non-binding signals. (Not supported) There was no evidence that any type of signaling improved group coordination, and none to suggest it was different between CT and CS.

- Hypothesis 3: Costly signals will result in more accurate estimates of market entry. (Supported) There was significant statistical evidence that subjects in CS made more accurate estimates than subjects in CT. There also was evidence to show that accuracy improved over time.

- Hypothesis 4: Signaling will not move group outcomes away from equilibrium predictions in the direction of Pareto optimal levels of entry. (Supported) The analysis showing no change in the mean difference in 
entry from equilibrium predictions across conditions and the analysis showing no change in the average payoffs across condition confirm that there was no movement toward Pareto optimal outcomes.

- Hypothesis 5: Players will attempt to use signaling strategically when signals are costless and non-binding. (Supported) The data showed that only $64 \%$ of subjects in CT were consistent in signal and action, compared to $98 \%$ in CS. This is clear evidence that the CT subjects were signaling strategically.

- Hypothesis 6: Signals that are costless and non-binding will be ignored and will have no affect on the decisions of subjects. (Not supported) There was exaggerated entry signaling in the CT condition. Subjects in the CT condition were less accurate than CS in estimating entry. Estimates were highly correlated with entry decisions. Thus, the evidence suggests that cheap talk was not ignored.

- Hypothesis 7: The number of entry decisions will increase with the market capacity. (Supported) This manipulation check was clearly supported.

- Hypothesis 8: With the introduction of costly signals, subjects will abandon dominated strategies ( $\# 2$ and $\# 3$ ) where signal and subsequent behavior are inconsistent. (Supported) Again, subjects were consistent $98 \%$ of the time in CS, providing clear support for this game theoretic prediction.

\section{Discussion}

In this discussion we address the research questions that were posed initially, provide suggestions for future research, and conclude with advice for management practitioners. The three research questions addressed in this paper were: 1) Do decision makers use signaling, and, if so, do they use it strategically or truthfully? 2) How do decision makers interpret and use the signals made by competitors? 3) How does signaling affect market coordination?

The results show that signaling was used frequently, and that when signals were costless and non-binding, many subjects signaled strategically. The results also indicate that exaggerated signaling in Condition CT did not diminish with time. Why not? Recall that game theoretic reasoning on the use of signaling suggests that it can be used to improve group coordination and payoffs. Clearly there was no evidence the group was moving towards Pareto optimal outcomes. Why continue to signal when such efforts were not improving group coordination? One explanation is simply that subjects were introducing noise into the system to make things more difficult for other participants. A second explanation is that subjects believed that entry signals could deter other entry and leave profitable entry opportunities. Neither of these explanations is consistent with game theoretic predictions. If cheap talk is not going to be used to coordinate a group on a Pareto superior outcome, then, game theory suggests, cheap talk 
should be ignored since it is not a credible entry-deterring tactic. Thus, while game theoretic predictions did amazingly well in predicting the aggregate number of entrants, the theory fared poorly in explaining individual behavior.

Subjects clearly used signaling results to estimate the number of market entrants. The lack of better estimates by subjects is a puzzling result for the following reasons. Aggregate entry was highly correlated with market capacity in both CT and CS conditions. This high correlation was achieved in the early rounds of the experiment and persisted throughout. Subjects were paid in every trial for accurate estimates and entry decisions and received immediate feedback regarding outcomes and payoff. Given the incentives and relevant feedback, subjects should learn quickly that the best estimate of the aggregate number of entrants was the market capacity (c) for that trial. As the results show, there was significant estimate error and the error was greater in the CT condition. The most plausible explanation for these results is that subjects were being influenced by signaling results, and the exaggerated entry signals in the CT condition made the estimation task even more difficult.

The aggregate effect of signaling on market coordination was minimal. Although signaling has been shown to have an effect in simpler, two-person coordination games, our findings suggest that signaling was of little consequence in this game; aggregate entry decisions tracked closely the levels predicted by Nash equilibrium. However, this result should be viewed with caution. In the three SRS groups used for comparison and the four signaling groups reported in the present study, the correlations between $\mathrm{c}$ and e across block ranged from 0.77 to 0.99 . Clearly, there was little room for much improvement toward the equilibrium prediction. Finally, we find no evidence that signaling moved the group toward Pareto optimal levels. Signaling clearly was not used as a coordinating mechanism to improve overall group payoffs.

The experimental design employed here allowed us to track signal, estimate, and entry decisions at the individual level. This collection of individual data provides a much richer data set than could be gathered with archival data. Unfortunately, the current design was limited in that it only allowed us to suggest aggregate correlations and was not able to better illuminate the individual decision making process. The design prevented conclusions to be drawn regarding exactly why subjects chose to enter or how subjects interpreted competitor signals. These shortcomings suggest directions for future research. First, future studies should attempt to better tease out the cognitive processes subjects are using in making entry decisions. The strictly rational approach of game theory is insufficient to explain individual decision making and should be supplemented with other theoretical paradigms. These studies also might consider collecting more detail data on judgment and decision processes. Second, to better assess the affects of signaling on coordinating aggregate group outcomes, future research efforts should consider making subjects aware of Pareto optimal outcomes. Since subjects in the present study likely did not recognize opportunities for improving group coordination, the use of signaling appears to have been primarily 
strategic. Third, to allow for reputation building to increase signal credibility, future designs should report the consistency in signaling and entry decisions at the individual level. Fourth, group size could be varied, as coordination always is more difficult in large groups. Fifth, the types of signals available to decision makers can be manipulated. For example, a cost could be imposed for making a signal, rather than deviating from a signal, as in the present study. Finally, to ensure better generalizations, our results could be augmented by those of field researchers interested in the dynamics of market entry.

What insights can we draw from these results for management practitioners? Practitioners that actually must make market entry decisions know how risky such decisions can be. Entry decisions depend on many variables such as market size, expected demand growth, barriers to entry, technological developments, and ultimately the number of other likely entrants. We cite just one example of how difficult and costly mistakes can be. In the 1990s technology boom, many firms rushed to enter and build fiber optic networks to carry internet traffic. These entry decisions were driven by overly optimistic growth rates of internet traffic and an incomplete understanding of how much capacity was being added by competitors. The net result is that as of 2002 , only $2.7 \%$ of the installed fiber actually is being used, and some believe that much of the capacity never will be used (Dreazen, 2002). Clearly this market failed to optimally coordinate market entry decisions, and that has led to numerous bankruptcies in the telecom sector.

Given the importance of market entry decisions, we offer suggestions to practitioners based on the results of our experiments. It is generally in the interests of all involved that market coordination is achieved and substantial over-entry avoided. Signaling can be very useful when it provides vital information to the market that allows others to make better and more rational decisions. Our results show that costly and credible signals provide valuable information to participants, which allows them to make more accurate estimates of the likely number of entrants. We suggest that practitioners should provide costly signals to the market to indicate credible intentions. This will allow others to take such information into account when making entry decisions. We further suggest that practitioners should be very careful in the use of costless signals as a strategic tool. The positive motivation for using costless signals is to deter other entry so that the market is under served and excess returns are then available. In our experiments, we find no evidence that costly signals were effective in deterring entry. We suspect that cheap talk is even less effective in influencing seasoned market participants than it was in influencing college students in a laboratory experiment. The negative consequences of using cheap talk are that it introduces noise into the system, increases the difficulty of the estimation task, and increases the probability of significant over-entry, and thus low returns, for all in the market. Thus, we suggest that the cost and potential risks of using cheap talk significantly outweigh the possible short-term benefits that it might provide. Finally, it may be very difficult for managers to identify coordination opportunities 
that yield Pareto superior outcomes. Our results suggest that decision makers either did not recognize alternative outcomes that were superior, or were unable to achieve them because the communication channels were flawed. Given this, we suggest that market participants try to recognize and appreciate that some situations of under entry may be, in fact, Pareto superior outcomes. Rather than rushing to enter markets that provide normal returns, participants might want to learn to be smart competitors and share different markets that provide Pareto superior returns. Finally, we suggest participants broaden and deepen communication channels to allow for the most effective signaling.

\section{References}

Ackerlof, G. (1970). The market for lemons: Quality uncertainty and the market mechanism. Quarterly Journal of Economics, 84, 488-500.

Ashton, R. H. \& Kramer, S. S. (1980). Students as surrogates in behavioral accounting research: some evidence. Journal of Accounting Research, 1-13.

Campbell J. P. (1986). Lab, fields, and straw issues. In E. A. Locke (Ed.). Generalizing from laboratory to field settings (269-279). Lexington, MA: Lexington Books.

Camerer, C. F. (1991). Does strategy research need game theory? Strategic Management Journal, 12, 137-152.

Camerer, C. F. \& Lovallo, D. (1999) Overconfidence and excess entry: an experimental approach. American Economic Review, March.

Cooper, R., De Jong, D., Forsythe, R., \& Ross, T. (1989). Communication in the battle of the sexes: some experimental results. Rand Journal of Economics, 20 (4), 568587.

Cooper, R., De Jong, D., Forsythe, R., \& Ross, T. (1992). Communication in coordination games. Quarterly Journal of Economics, 53, 739-771.

Dreazen, Y.J. (2002). Telecom carriers were driven by widely optimistic data on internet's growth rate. Wall Street Journal, September 26, B1-B8.

Farrell, J., (1987) Cheap talk, coordination, and entry. Rand Journal of Economics, 18 , 34-39.

Farrell, J., (1995). Talk is cheap. American Economic Association and Proceeedings, May, 186-190.

Fudenberg, D. \& Kreps, D. M. (1993). Learning mixed equilibria. Games and Economic Behavior, 5, 320-367. 
Gordon, M. E., Slade, L. A., \& Schmitt, N. (1986). Student guinea pigs: porcine predictors and particularistic phenomena. Academy of Management Review, 12 (1), 160-163.

Greenberg, J. (1987). The college sophomore as guinea pig: setting the record straight. Academy of Management Review, 12 (1), 157-159.

Grossman, S. (1981). The role of warranties and private disclosure about product quality. Journal of Law and Economics, 24, 461-83.

Gulati, R. (1995) Does familiarity breed trust? The implications of repeated ties for contractural choices in alliances. Academy of Management Journal, 28 (1), 85-112.

Kreps, D. (1994). Signaling. In R. Aumann \& S. Hart (Eds.) Handbook of game theory with economic applications. New York: Elsevier.

Locke, E. A. (1986). Generalizing from laboratory to field: Ecological validity or abstraction of essential elements. In E. A. Locke (Ed.). Generalizing from laboratory to field settings (269-279). Lexington, MA: Lexington Books.

Milgrom, P. \& Roberts, J. (1982). Limit pricing and entry under incomplete information. Econometrica, 50, 443-459.

Nash, J. F., Jr. (1951). Non-cooperative games. Annals of Mathematics, 54, 289-295.

Ochs, J. (1995). Coordination problems. In J. H. Kagel and A. E. Roth (Eds.), of experimental economics. Princeton, NJ: Princeton University Press.

Oster, S. (1994). Modern competitive analysis, 2nd Edition. Oxford, New York.

Porter, M. (1996). What is strategy? Harvard Business Review. November-December 1996.

Postrel, S. (1994). Burning your britches behind you: can policy scholars bank on game theory. In R. Rumelt, D. Schendel, and D. Teece (Eds.), Fundamental issues in strategy. Boston, MA: Harvard Business School Press.

Rapoport, A. (1995). Individual strategies in a market entry game. Group Decision and Negotiation, 4, 117-133.

Rapoport, A.\& Koput K. (1993). Market entry and the emergence of new industries: Experimental studies. National Science Foundation grant proposal, October.

Rapoport, A., Seale, D., Erev, I., \& Sundali, J. (1997). Equilibrium play in large group market entry games. Management Science, 44 (1), 119-141. 
Rapoport, A., Seale, D., \& Ordonez, L. (2002). Tacit coordination in choice between certain outcomes and endogenously determined lotteries. Journal of Risk and Uncertainty, $25(1), 21-45$.

Rapoport, A., Seale, D.A., \& Winter, E. (2000). An experimental study of coordination and learning in iterated two-market entry games. Economic Theory, 16, 661-687

Roth, A. (1995). Introduction to experimental economics. In J. H. Kagel \& A. E. Roth (Eds.), Handbook of experimental economics. Princeton, NJ: Princeton University Press.

Saloner, G. (1994). Game theory and strategic management: contributions, applications, and limitations. In R. Rumelt, D. Schendel, \& D. Teece (Eds.), Fundamental issues in strategy. Boston, MA: Harvard Business School Press.

Seale, D. \& Sundali, J., (1999). Cheap talk in a large group coordination game. In Budescu, D., Erev, I., \& Zwick R. (Eds.), Games and human behavior. Essays in honor of Amnon Rapoport, pp. 173-200, Lawrence Erlbaum Associates, New Jersey.

Spence, A. M. (1974). Market signaling. Cambridge, MA: Harvard University Press.

Sundali, J., Rapoport, A., \& Seale, D. (1995) Coordination in market entry games with symmetric players. Organizational Behavior And Human Decision Processes, 64 (2), 203-218.

\section{Footnotes}

Since the use of student subjects in experiments is controversial to some, we offer the following comments. Campbell's (1986) seminal paper, where he concluded that "Perhaps college students really are people... why their disguise fools many observers into thinking otherwise is not clear" (p.276), led to a number of papers addressing the external validity of behavioral experiments. Gordon, Slade and Schmitt (1986) found that there are between group differences in experiments using students and nonstudents, and based upon this finding concluded that journal gatekeepers should be careful in accepting such research. Greenberg (1987) countered that Gordon et al. (1986) missed the fundamental point of laboratory research and that one study using any homogeneous group of subjects was not generalizable to a universal population. While this broad debate continues today, our view is that experiments requiring domain-specific knowledge or experience may not be suitable tasks if the goal of the research is to generalize results from students to professionals. However, there is also much evidence (Ashton \& Kramer, 1980) that shows that when the experimental task involves basic information processing and/or decision making skills, college students make decisions very similar to those of the general population, including professional managers. Locke (1986) argued that if the purpose of a laboratory experiment is to study fundamental psychological or cognitive 
processes, then the similarities between students and employees are greater than are the differences between the groups. In the research presented here, we believe the fundamental contribution is the development and testing of a rigorous game theoretic model. As such, our subject pool of students is appropriate since their basic cognitive processes are more important to the internal validity of the study than is their domain specific knowledge.

${ }^{2}$ In advertisements for the experiments subjects were told they could earn up to $\$ 50$ by participating in a two-hour experiment. We consider a wage of $\$ 25$ per hour for most students to be "a considerable sum of money."

${ }^{3}$ In subsequent analyses, the data were collapsed over groups since tests showed no significant group effect on signals or entry decisions. A small but significant group effect existed in the costly signaling condition on estimates, but there was no group effect in the cheap talk condition on estimates. Additional analysis determined this one group effect to be irrelevant to the analyses of interest.

${ }^{4}$ An additional ANOVA not reported here showed that subjects in the CT condition had slightly higher estimates of the number of entrants across both market capacity and block than subjects in the CS condition.

${ }^{5}$ To compare our results directly to SRS, we treated their data as a third condition. The differences between the experiments were discussed above.

James A. Sundali is Associate Professor of Strategic Management at the University of Nevada, Reno. In addition to teaching courses in strategic management, he offers electives in bargaining and negotiation, and leadership insights from film and literature. His research interests include experimental economics, behavioral finance, and gaming.

Darryl A Seale is Associate Professor of Management at the University of Nevada Las Vegas. He received his MS and PhD from the University of Arizona, and his MBA from Penn State. His research has been supported by grants from the National Science Foundation, and the Hong Kong University of Science and Technology. His research interests are in behavioral game theory, strategic decision making and bargaining. He has published articles in Management Science, Games and Economic Behavior, Economic Theory, Organizational Behavior and Human Decision Processes, and Journal of Economic Behavior and Organization. 